BOOK REVIEW

\title{
ETHNICITY vS. NATIONALISM: THE DEVOLUTION DISCOURSE IN SRI LANKA
}

\section{PARTHA GHOSH}

Sage Publications in Association with Indian Council for World Affairs, New Delhi, 2003, pp.501

Reviewed by S.T. Hettige

Partha Gosh sets out the main objective of his book as follows:

Devolution received unprecedented currency with the emergence of Chandrika Kumaranatunga on the political scene in 1994 with the victory of her coalition People's Alliance (PA) with general election, which was soon followed by her own victory at the presidential polls. She made it the central point of her election campaign that a historic injustice has been done to the Tamil community in the island and that she would solve the problem permanently through a massive dose of devolved powers to them after working out a federal structure for the country. How and why she failed in her mission is the subject of this book (p. 23).

When one goes through the book from his introduction through various chapters to the conclusion, one realizes how modest the author has been in introducing his book to the reader. The author has, in fact done a remarkable job in contextualizing the conflict in Sri Lanka in terms of theoretical analysis, surveying of the historical backdrop, examination of secondary sources, use of primary data and, most of all, presenting perhaps one of the most balanced treatments of the subject so far. The book is written in an extremely lucid language with little or no jargon, making it a pleasure to read. The style of writing has in no way compromised the rigorousness and the depth of the analysis. 
This review is not intended to provide a detailed commentary on each of the chapters dealing with various aspects of the subject. This would require a deep understanding of a range of areas such as history, geo-politics, comparative government, etc. I do not claim to possess such an understanding. Therefore, I wish to focus my attention on the broader aspects of the author's analysis and offer some comments.

How did the Sri Lankan ethnic conflict reach its present impasse? The author provides a detailed account of the process of its evolution, tracing its early beginnings through the colonial period to post-independence developments upto more recent years. He outlines the contribution of various factors, including the role of various intellectual groups representing diverse interests as well as different schools of thought. Overall, the outcome of the interplay of various factors and forces has not been a reconciliation of the differences leading to a workable solution. Hence; the continuing impasse, with no clear prospect of finding a peaceful settlement in the near future. In this regard, the author's analysis is informative and highly instructive. It helps the reader to appreciate the complexities and the difficulties involved. Those who genuinely desire a peaceful solution will find this analysis very useful and therefore, is very good material for public education and discussion. On the other hand, those whose interests are sectarian will not appreciate such an analysis, for they would only find the opponents responsible for the situation. The situation is naturally complex, given the fact that ideas and interests are no longer separated in a conflict that involves an interplay of diverse ideological and interest groups.

Let me begin with a commentary on a few issues of an academic nature. The issues are related to:

a) The notion of objectivity in social science analysis

b) Apparent polarity between science and politics, and

c) Limitations of social science analysis in the face of ground realities. 
The author brings these issues to the foreground, thus making his perspective a concrete and realistic one. In the analysis provided by the author, the latter does not pursue an abstract notion of objectivity. Instead, he attempts to reach a reasonable level of objectivity by laying bare, divergent viewpoints, so that the reader can make his or her own judgment, without being unduly influenced by the author's own interpretation.

The second issue, namely, the nexus between science and politics, is highly relevant for any analysis of the subject at hand. Given the fact that the ethnic conflict is as much a contest between two divergent interpretations of its genesis and evolution as the result of an actual chain of events unfolding over a long period of time, involving a large mass of real people and actors, it is natural for both social scientists as well as political actors to get involved. The analysis of the conflict is thus not the prerogative of the social scientists alone. On the other hand, political actors do not confine themselves to the task of political bargaining either. They themselves would invoke ideas coming from the social science discourse in order to support their own sectarian interpretations. In this regard, much of social science analysis is also not innocent. Social scientists coming from diverse ethnic and other backgrounds do not necessarily stand above their own community interests. So, what we observe in reality is a very complex relationship between pragmatic politics and social science interpretations.

The result is that objectivity is not always maintained. In fact, what is at times observed is a deliberate attempt to use social science to suit sectarian political agendas. Those social scientists who are personally involved in sectarian conflicts themselves are likely to use their positions to serve the interests of the groups they represent. There are also instances where the positions that the intellectuals take reflect divergent ideological stances rather than empirically-grounded propositions.

And finally, we have to deal with the limitations of social science analysis itself. In dealing with situations of socio-political conflict, ground realities can change rapidly and in unexpected ways. Politicians 
as well as social scientists are often overtaken by events that can even be of a shocking nature. In such situations, politicians usually take the upper hand as the time available for response is short. Social scientists are often relegated to the background in such situations.

What is outlined above are three important issues that Partha Ghosh has drawn our attention to, in the context of his analysis of the Sri Lankan conflict. The way he responds to these three issues naturally makes the social scientist more humble and the social and political analysis modest. Yet, when we observe the depth and the wide ranging nature of his own analysis, he certainly appears to be too modest as a social scientist. While one can appreciate the point he makes about the objectivity and impartiality of social science analysis, his own treatment of the empirical data, and the healthy distance he maintains with regard to the subject matter he deals with, one can equally be convinced that the social scientist, if not too personally involved, can engage in fairly objective analysis and interpretation. In fact, Partha Ghosh offers a remarkably balanced social science analysis of the issues involved.

On the other hand, his portrayal of the extent to which social and political analysis and politics are inter-twined in Sri Lanka with respect to one of the most intractable issues in its recent history and the methodological observation he makes on the nexus between social science and politics seem rather reasonable. In fact, the roles of intellectuals and political activists are so often interchanged that it is often not clear whether one is playing the role of a social scientist or that of a sectarian political activist. While this is certainly not the most desirable image for a profession that is expected to maintain certain standards with regard to objectivity, impartiality, truth and universality, the author's own brave effort to provide a social science perspective on the Sri Lankan issue has given some respectability to the profession.

It is significant that Partha Ghosh's book has a strong empirical orientation and goes beyond a mere conceptual analysis. He is careful to back his arguments with detailed empirical facts or data so that they do not remain mere opinions. This is what can be in fact, found 
throughout this publication. Though many examples can be cited, one such example can illustrate this point. This relates to the comparison that many analysts make between India and Sri Lanka, in order to argue that Sri Lanka can learn a lot from India. The author's position in this regard is that the two situations are hardly comparable. In chapter IX, he provides a convincing argument against copying the Indian model. The empirical facts he presents are linked to political, constitutional, spatial and international dimensions (p. 391). In this regard, his comparisons between the Indian system of social stratification linked to the caste system and that of Sri Lanka, which is largely ethno-religious based is extremely illuminating.

Besides various other strands of analysis that can be found in "Ethnicity vs. Nationalism", a broadly political economy perspective that the author adopts has enabled him to take into account the structural roots of the conflict that have not figured prominently in the public and intellectual discourse on devolution in Sri Lanka. The author's emphasis on structural factors is evident from his conclusion that "the question is basically developmental in nature" (p. 395).

To arrive at the above conclusion, the author quotes Godfrey Gunetilleke who argues that the main source of communal conflict is the fierce competition for elite positions in our society (p. 395). This argument is based on empirical data on the changing composition of public sector employment. Another issue that is emphasized by the author is that of land alienation, particularly in the Eastern Province. This is also an important area of competition for resources.

But, then, the question arises as to why the competition has evolved on ethnic lines? His answer is the obvious one. The Tamils are not only ethno-linguistically distinct from the Sinhalese but are largely concentrated in one geographically contiguous region as well. The author correctly identifies two additional, yet crucially important factors that have set the two communities apart, namely the way in which Sri Lankan politics evolved after independence leading to a polarization of political parties on ethnic lines contributing to an increasing alienation of Sri Lankan Tamil parties from the centre, and the obvious association 
of the Tamil minority-struggle with a distinct geographical region. What should also be added here is the fact that the conflict developed over several decades, at times declining to a level of extreme cruelty and unprecedented violence and destruction.

The devolution debate centred around the ethnic conflict is one that was bound to be contentious and problematic. It cannot be expected to follow a sober, rational path chartered by independent social scientists. In fact, the diversity of opinions and ideas that have figured within the devolution discourse is a reflection of the wide-ranging nature of participants coming from diverse backgrounds. A social scientist with a commitment to objectivity and independent empirical analysis enters such a debate at his own risk. Partha Ghosh has been brave enough to enter the debate and make a remarkable effort to apply the tools of social science analysis. He goes beyond the analysis and offers his own ideas as to how the Sri Lanka conflict should be resolved. These ideas are sketchy and do not constitute a comprehensive plan of action, particularly in view of the fact that his own analysis has covered a very wide field. This is no doubt due to his realization that macro politicoeconomic factors cannot be easily addressed. On the other hand, if the macro picture remains what it is, it is doubtful whether his formula of a three stage solution will ever be considered by the contending parties.

It is significant that the author's proposal is essentially aimed at confidence building among the parties to the conflict. His emphasis on civil society involvement in the initial reconciliation process with no participation of political actors is interesting. It is equally interesting that he wants the political process to unfold in the third stage, to work on a power sharing arrangement, to be followed by the drafting of a suitable constitution and its ratification by the people at a referendum. What the author, in effect has done is to reverse the whole process of reconciliation, leaving the issue of a final settlement to be taken up at the end, rather than at the beginning. On the other hand, Sri Lanka's prospects for finding a negotiated settlement seem to depend on two critical factors, namely the LTTE's stance and the macro political situation in the country. The two factors are perhaps not totally independent of each other though one gets the sense that they are 
influenced by their own dynamics. It is with a sense of deep uncertainty about the future of Sri Lanka that the author concludes his book.

The author has added a brief postscript to the book to capture the developments after the fall of the PA regime in 2001 and the establishment of the UNF regime led by the UNP under the leadership of Ranil Wickremasinghe. On the other hand, by the time I began this review that regime was no more. The regime had lasted for just over two years when the President dissolved Parliament and ordered fresh elections at which a new PA regime was elected. All these events point to the nature of macro-politics in the south and the fact that social scientists and politicians alike are constantly overtaken by events.

The most significant event under the UNF regime of 2001 was the signing of a peace agreement with the LTTE. In spite of allegations and counter-allegations with respect to violations of the ceasefire agreement, the agreement itself has been holding, in spite of change of regimes. While there is no clear prospect of finding a negotiated settlement in the near future, the author agrees with a commentator in Colombo that the LTTE has been able to consolidate its position in the areas under their control, perhaps moving towards political autonomy without a formal process of negotiation and power sharing. The Sri Lankan situation is perhaps just another instance where disciplined social science analysis has a very limited role to play while sectarian politics, vested interests and unexpected events determine what happens on the ground. 